\title{
COACHING EFFICACY AND LEADERSHIP STYLE AMONG BULGARIAN FOOTBALL COACHES
}

\author{
Tatiana Iancheva, Gancho Prodanov \\ National Sports Academy „Vassil Levski”, Sofia, Bulgaria
}

\begin{abstract}
Coaches' confidence in their own skills, their awareness of their emotions and the ability to control them, as well as their choice of behavior, according to a number of authors, influence their realization and the achieved sports results.

The aim of the present study is to reveal the interdependencies between Coaching Efficacy, Emotional Intelligence and Leadership Style among Bulgarian football coaches.

Methods: The research was done among 50 football coaches aged between 23 and 45 years with different level of qualification. In order to fulfill the aim, we used: 1) Coaching Efficacy Scale (CES), Feltz et al., 1999; 2) Emotional Intelligence Scale (EIS), Schutte et al., 1998; 3) Revised Leadership Scale for Sport (RLSS), Zhang et. el., 1997.

Results and discussion: The results reveal significant correlation interdependencies between the subscales of Coaching efficacy, Emotional Intelligence and part of the subscales of Leadership style, as well as between the subscales of Emotional intelligence and Leadership style. In this sense, our results confirm the data in the literature. We have found a slight correlation between Coaching efficacy and Leadership style, which is different from the published data.

There are significant differences along some of the researched indexes depending on licenses, ages of players, coaching experience, experience as a player.

The results from the regression analysis reveal that Emotional intelligence serves as a predictor of Coaching efficacy and Leadership style. Coaching efficacy does not influence directly the subscales of Leadership style.
\end{abstract}

Key words: Coaching Efficacy, Leadership style, Coaching behavior, Football coaches

\section{INTRODUCTION}

Coaches' confidence in their own abilities and their behaviour have a significant effect on athletes and can influence positively or negatively their performance (Feltz et el., 1999).

Bandura (1977) created the theory of Self-efficacy and pointed out its 4 main sources - Past Performance, Verbal Persuasion, Vicarious Experience, Emotional States (Bandura, 1977, 1994). In line with Bandura's concept (1977) about Self-Efficacy, Feltz et al. $(1994,1999)$ created and presented a sport-oriented model for coaching efficacy expectations which "provides an initial frame for research on the relations among coaching efficacy expectations, coaches' behavior, motivation, and athletes' performance" (Iancheva, 2012). The authors de- fined coaching efficacy expectations as "the degree to which coaches believe they have the capacity to influence their athletes' training and performance" (D. Fltz, M. Chase, S. Moritz \& P. Sullivan, 1999). Feltz et al. (1999) introduced a model (table 1) which included four dimensions - game strategy - coaches' confidence in their abilities during a competition to lead their team to a successful performance; motivation - coaches' confidence in their abilities to influence the psychological processes and conditions of their athletes and to stimulate their activity; technique - coaches' confidence in their abilities to build technical skills and habits in the football players; character building - coaches' confidence in their abilities to influence their athletes' positive attitude to sport (Feltz et al., 1999).

Table 1. Conceptual Model of Coaching Efficacy, Feltz et al.(1999)

\begin{tabular}{|c|c|c|}
\hline Sources of Coaching efficacy & Coaching efficacy dimensions & Outcomes \\
\hline$>$ Extent of coaching & $>$ Game strategy & $>$ Coaching behavior \\
\hline experience/preparation & $>$ Motivation & $>$ Player/team satisfaction \\
\hline$>$ Prior success (won-lost record) & $>$ Technique & $>$ Player/team performance \\
\hline $\begin{array}{l}>\text { Perceived skill of athletes } \\
\text { School/community }\end{array}$ & $>$ Character building & $>$ Player/team efficacy \\
\hline
\end{tabular}


Chase, Feltz, Hayashi, and Hepler (2005) widened the sources and added more: players' development, coaches' development, knowledge/preparation, leadership skills, player support, and past experiences (Chase et al., 2005). Malete and Feltz (2000) reported that coaches who had taken part in a particular training program and those with certificates had significantly higher marks for efficacy (Malete \& Feltz, 2000).

Conceptually, coaching efficacy is considered to be a cognitive mediator between sources and outcomes. Côté and Gilbert (2009) suggest that coaching effectiveness is an interaction of a coach's knowledge, athletes' outcomes and coaching contexts (Côté and Gilbert 2009).

Horn $(2002,2008)$ formulated a working model of coaching effectiveness. In the center of his model is coaches' behavior and expectations, their beliefs and goals (Horn, 2002, 2008). The Horn model is based on three assumptions. The first is that antecedent factors (i.e., sociocultural context, organizational climate, and coaches' personal characteristics) influence coaches' behaviors indirectly through coaches' expectancies, beliefs, and goals. Second, coaches' behaviors directly influence athletes' evaluations of their coaches' behaviors and team performance. Finally, the effectiveness of coaches' behaviors is influenced by situational factors and athletes' individual differences. A large body of studies (Horn, 2002; Hwang et al., 2013; Kavussanu et al., 2008; Myers et al., 2005; Sullivan \& Kent, 2003; Sullivan et al., 2012) have provided empirical evidence that Coaching Efficacy was a strong predictor of Leadership Behavior.

Feltz et al. (1999) found out that coaches with higher coaching efficacy used more encouraging behavior towards their players (Feltz et el., 1999). A survey of Myers et al. (2005) supported those claims (Myers et al., 2005). Sullivan and Kent (2003) demonstrated that coaches who were rated as high efficacy engaged in more teaching and instructional behavior's (Sullivan \& Kent, 2003).

Barrow (1977) defined the leadership as the behavioral process of influencing individuals and groups toward set goals. Nowadays, Whitmore (2003), defined leadership as the way to unlock a person's potential so as to maximize own performance.

Smoll, Smith, Curtis and Hunt (1978) created a mediational model of leadership, which was based on: coaches' behavior, players' perceptions and recollections, and players' evaluative reactions (Smoll, Smith, Curtis and Hunt, 1978). The effects of coaching behaviours are mediated by the meaning the players attribute to them. Effective leadership is described as a function of the traits of the persons entering the relationships, i.e. the coach and the athletes, and of the situation (Chelladurai \& Carron, 1978). Leadership style of any coach is a major factor which affects the performance of a person or a group of people, directly or not (Vincer \& Loughead, 2010). The surveys based on the model of coaching effectiveness (Hwang et el., 2013; Teques et el., 2019) among coaches from different kinds of sports established the direct relation between Coaching Efficacy and Leadership Style.

The aim of the present research is to study the interdependence between coaching efficacy and leadership style among football coaches.

\section{METHOD}

\section{Participants}

The research was done among 172 football coaches aged between 20 and 56 years who differed by: age, license, age group of their athletes, coaching experience, and experience as football players. At the beginning of the research all participants were informed about the aim of the survey and agreed to take part in it.

\section{Measures}

In order to fulfill the aim of the research we used:

Background information.

Coaching Efficacy Scale (CES; Feltz et al., 1999), adapted for Bulgarian conditions by T. Iancheva, 2012. The CES - totaling 24 items (where items are rated on a 10-point scale). It includes four subscales: Motivation efficacy, Game strategy efficacy, Character building efficacy, Teaching technique efficacy.

Revised Leadership Scale for Sport (RLSS; Zhang et. el., 1997). The six-factor structure of leadership behaviors is represented through 60 items that are measured using a 5-point Likert-type scale - Democratic behavior, Positive feedback behavior, Situation consideration behavior, Teaching and instruction behavior and Social support behavior (e.g., encourage close and informal relationship with the athletes) and Autocratic behavior. 


\section{Statistical methods}

When processing the initial data from the research, we used statistical package SPSS 21 and made variation, correlation, comparative and regression analyses.

\section{RESULTS AND ANALY SIS}

The results from the variation analysis of the data (Figure 1) for coaching efficacy revealed that the subscales Technique efficacy $(M=7,96)$ and Motivation efficacy $(M=7,94)$ had the higher values, i.e. coaches feel the most confident in their abilities to provide the necessary instructions, to build technical skills, and to motivate their players in order to stimulate their activity and maintain their confidence. This is an interesting fact as regards the circumstance that in Bulgaria, in most cases, after failures, in interviews and at social events coaches often explain the bad results with lack of or insufficient motivation.

Character building efficacy $(M=7,81)$ is the next subscale - coaches' belief in their abilities to influence the positive attitude and to build certain personal qualities. The subscale Game strategy efficacy had the lowest values ( $M=7,24)$. It is of fundamental significance for the essence of play and reflects coaches' abilities to take critical decisions in competition in order to lead the team to successful results. The obtained results confirm our previous surveys among Bulgarian football coaches (Iancheva \& Prodanov, 2017, 2018).

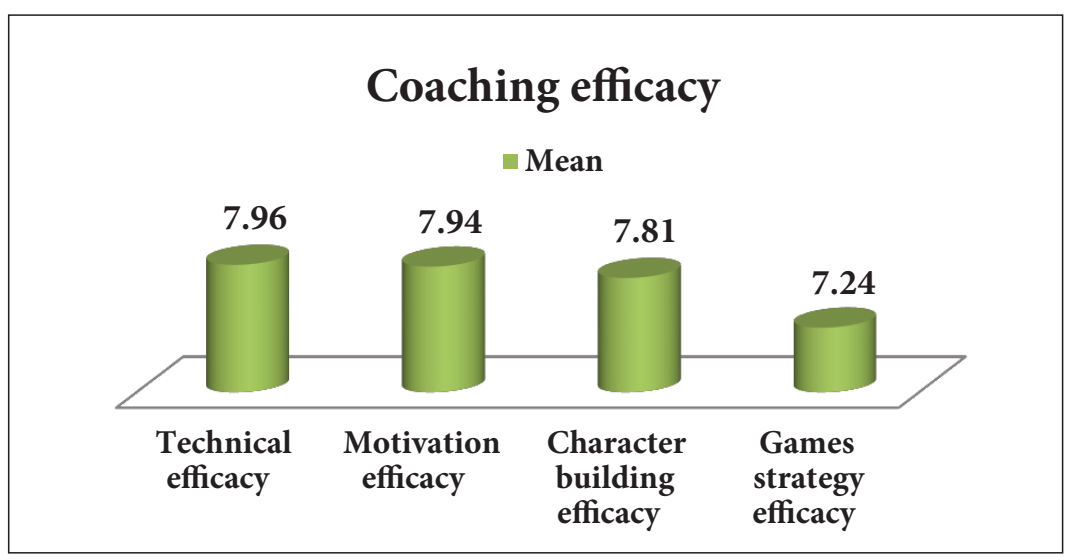

Figure 1. Coaching Efficacy - Descriptive statistics of study variables $(n=172)$

The results show that the subscale Training and instruction behavior was leading among the researched leadership styles - $\mathrm{M}=4.17$ (figure 2). Coaches most often prefer behavior related to giving guidelines and corrections about the team's performance in training and competition. They consider their players' possibilities and are willing to change the load and difficulty of the different play elements Situational consideration behavior - $\mathrm{M}=$ 4.14. Coaches more rarely choose a behavior related to encouragement and evaluation of their players' success (Positive feedback behavior - $\mathrm{M}=4.04$ ) as well as personal advice (Social support behavior $M=4)$. The researched coaches are more willing to take decisions self-assertively.

\section{Leadership style}

Mean

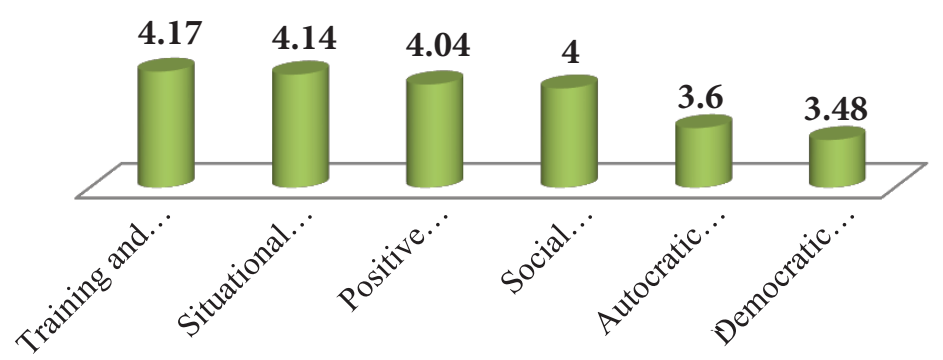

Figure 2. Leadership Style - Descriptive statistics of study variables $(n=172)$ 
The results from the correlation analysis of the data (Table 2). There were no significant correlations berevealed significant correlation dependences between tween Democratic behavior and Autocratic behavior the subscales of coaching efficacy and leadership style and the subscales of Coaching Efficacy.

Table 2. Results from the correlation analysis of the data

\begin{tabular}{|l|l|l|l|l|l|l|l|l|l|l|l|}
\hline & ME & GSE & TE & CBE & TIB & DB & AB & SSB & PFB & SCB & TCE \\
\hline ME & 1 & & & & & & & & & & \\
\hline GSE &, $641^{* *}$ & 1 & & & & & & & & & \\
\hline TE &, $664^{* *}$ &, $676^{* *}$ & 1 & & & & & & & & \\
\hline CBE &, $544^{* *}$ &, $452^{* *}$ &, $464^{* *}$ & 1 & & & & & & & \\
\hline TIB &, $216^{* *}$ &, $316^{* *}$ &, $312^{* *}$ &, $155^{*}$ & 1 & & & & & & \\
\hline DB &, 079 &, 149 &, 067 &, 147 &,- 136 & 1 & & & & & \\
\hline AB &, 097 &, 072 &, 100 &, 110 &,- 016 &, $527^{* *}$ & 1 & & & & \\
\hline SSB &, $262^{* *}$ &, $295^{* *}$ &, $276^{* *}$ &, $219^{* *}$ &, $317^{* *}$ &, $462^{* *}$ &, $270^{* *}$ & 1 & & & \\
\hline PFB &, $170^{*}$ &, $239^{* *}$ &, $217^{* *}$ &, $161^{*}$ &, $315^{* *}$ &, $468^{* *}$ &, $269^{* *}$ &, $559^{* *}$ & 1 & & \\
\hline SCB &, $267^{* *}$ &, $312^{* *}$ &, $306^{* *}$ &, $365^{* *}$ &, $374^{* *}$ &, $440^{* *}$ &, $426^{* *}$ &, $528^{* *}$ &, $469^{* *}$ & 1 & \\
\hline TCE &, $864^{* *}$ &, $842^{* *}$ &, $827^{* *}$ &, $762^{* *}$ &, $298^{* *}$ &, 138 &, 115 &, $318^{* *}$ &, $238^{* *}$ &, $381^{* *}$ & 1 \\
\hline
\end{tabular}

Notes: ME - Motivation efficacy; GSE - Games strategy efficacy; TE- Technical efficacy; TIB- Training and instruction behavior; DB-Democratic behavior; AB- Autocratic behavior; SSB-Social support behavior; PFB Positive feedback behavior; SCB-Situational consideration behavior; TCE - Total coaching efficacy. ${ }^{*} p<0.05$ level (2-tailed); ${ }^{* *} p<0.01$ level (2-tailed)

The comparative analysis of the data revealed sta- behavior in comparison with those with shorter tistically significant differences along all indexes sports experience. There were significant differenc(Figure 3). Coaches with longer experience as fo- es along the factor age as regards Technique efficaotball players had significantly higher results along cy, Motivation efficacy, Character building efficacy the subscales: Technique efficacy, Motivation effi- and Total coaching efficacy. The coaches in the age cacy, Game strategy efficacy and Total coaching group 45-60 years had the highest values. efficacy, but they most seldom use Democratic
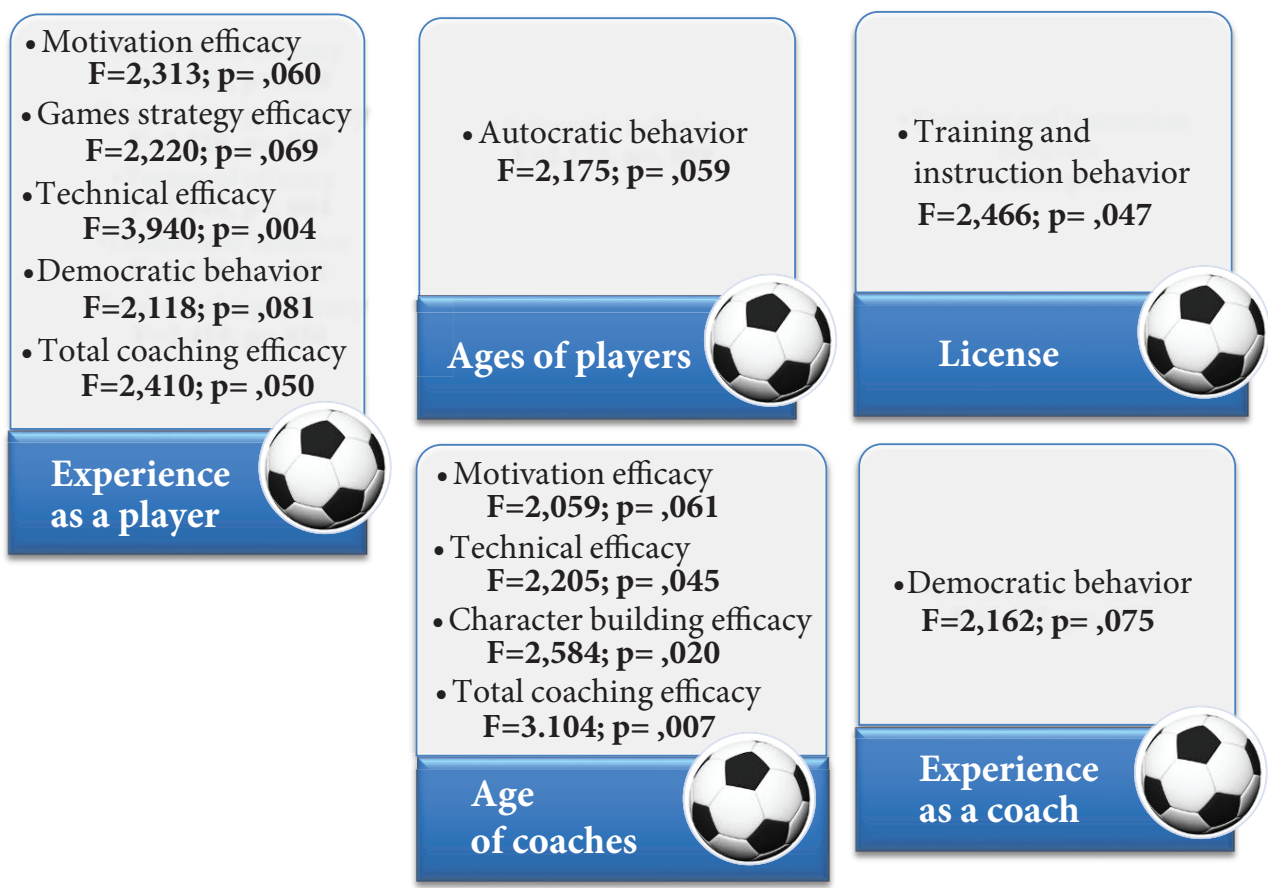

Figure 3. Comparative analysis of studied variables 
There were significant differences depending on qualification (acquired license) as regards Training and instruction behavior. There were also significant differences as regards the players' age. The coaches with work experience between 7 and 15 years had lower values of Democratic behavior compared to the other coaches.
The results from the regression analysis (figure 4) revealed that Motivation efficacy $\left(\beta=.294^{* * *}\right)$, Game strategy efficacy $\left(\beta=.226^{* * *}\right)$, Character building efficacy $\left(\beta=.220^{* * *}\right)$, Teaching technique efficacy $\left(\beta=.365^{* * *}\right)$ stimulate Situation consideration behavior. Game strategy efficacy influences Training and instruction behavior $(\beta=.316)$.

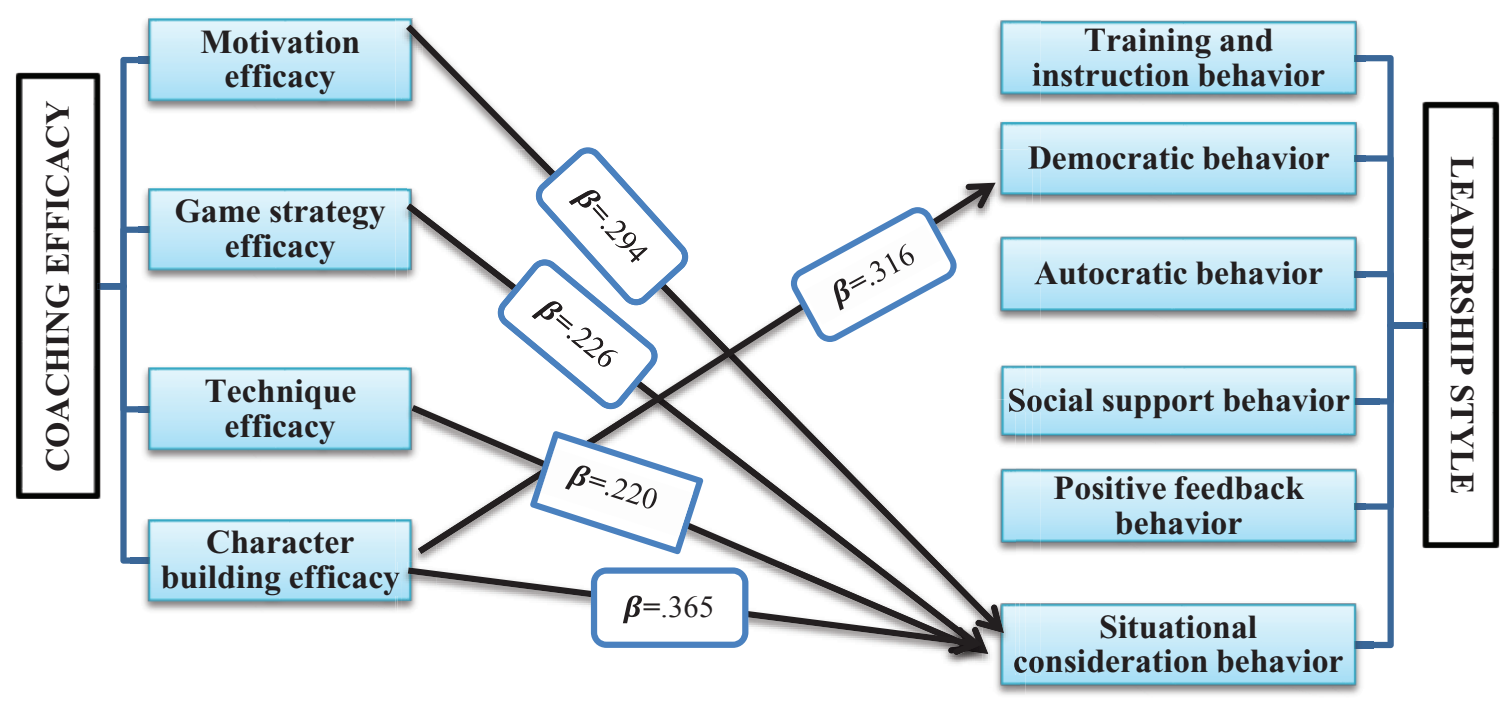

Figure 4. Regression analysis of studied variables $(n=172)$

\section{DISCUSSION}

The results from our research reveal a certain specificity. Our practical observations show that in most cases Bulgarian football coaches explain bad results with lack of or insufficient motivation. While the results show they feel the most confident along this component. Our results differ from those in literature. Kavussanu et el. (2008) established the lowest values for Motivation efficacy.

The technique of play in football is extremely important for achieving a positive result. At the same time, the data show the lowest results for coaching efficacy along the scale Game strategy efficacy. It is interesting that in sports such as football, where the game strategy and decision taking in constantly changing situations are critical for the final results, coaches have the lowest confidence.

One of the possible reasons for this is coaches' awareness of the importance of this component of coaching efficacy and their inability to cope with the constantly changing requirements related to game strategy management. The obtained data confirm our previous studies with Bulgarian coaches (Iancheva \& Prodanov, 2017, 2018) but differ from those published in literature (Kavussanu et el., 2008).

The preferred leadership styles among the researched coaches are Training and instruction behavior and Situational consideration behavior, related to providing guidelines and corrections, considering players' possibilities, change in loads and the difficulty of different play elements. Coaches more rarely choose Positive feedback behavior - a behavior evaluating successes and encouraging players. Coaches prefer to take decisions self-assertively.

The established age differences differ from the data in literature. The results show that the coaches aged between 46 and 50 years have significantly higher results for Technique efficacy, Motivation efficacy, Character building efficacy and Total coaching efficacy, in comparison to those aged between 20 to 25 years. Gioldasis et al. (2013) found out that younger coaches preferred to take decisions self-assertively while the older ones - democratically (Gioldasis et al.,2013).

Our preliminary hypothesis for significant differences as regards qualification was not justified. Only as regards Training and instruction behavior, 
coaches with "A" have significantly higher values, demonstrate greater erudition and competence compared to those with "C" license. The coaches, who are not currently working, are more willing to use Autocratic behavior. The coaches with 7-15year experience have lower values for Democratic behavior. These data differ from those obtained by Gioldasis et al. (2013), where the coaches with bigger experience preferred to use Democratic behavior (Gioldasis et al.,2013).

Both in the model for Coaching efficacy of Feltz et al. (1999) and in that of Horn (2002). Coaching efficacy is a predictor of coaching behavior. A large body of studies (Horn, 2002; Hwang et al., 2013; Teques et el., 2019; Kavussanu et al., 2008; Myers et al., 2005; Sullivan \& Kent, 2003; Sullivan et al., 2012) have provided empirical evidence that as a personality attribute, Coaching efficacy is a strong predictor of Leadership Style. Our results, to a certain extent, differ from those in literature. The regression analysis revealed that all subscales of Coaching efficacy stimulate only Situation consideration behavior. Game strategy efficacy influences only Training and instruction behavior. Sullivan \& Kent (2003) established that Motivation efficacy and Teaching technique efficacy influenced all subscales of leadership style (Sullivan \& Kent, 2003).

We should point out some limitations of our research. It was done only among football coaches. Future surveys with larger number of coaches from different kinds of sports could shed more light on this important for theory and practice issue.

\section{REFERENCES}

Bandura, A. (1977). Self-Efficacy: Toward a unifying theory of behavioral change, Psychological Review.

Bandura, A. (1994). Self-efficacy. Encyclopedia of human behavior. Vol. 4, pp. 71-81.

Barrow, J. C. (1977). The variables of leadership: A review and conceptual framework. Academy of Management Review, 2, pp.231-251.

Chase, M.A., Feltz, D.L., Hayashi, S.W. \& Hepler, T.J. (2005). Sources of coaching effi cacy: The coaches perspective. International Journal of Sport and Exercise Psychology, 1, pp. 7-25.

Chelladurai, P. (1978). A contingency model of leadership in athletics. Unpublished doctoral dissertation, University of Waterloo, Waterloo, Ontario.

Chelladurai, P., \& Saleh, S. D. (1980). Dimensions of leader behavior in ports: development of a leadership scale. Journal of Sport Psychology, 2, pp. 34-45.

Chelladurai, P., Carron, A. V. (1978). Leadership. CAHPER, Sociology of Sport Monograph Series. Calgary, Alberta, Canada: University of Calgary.

Chelladurai, P. (2007). Leadership in Sports, in: Tenenbaum, G. and Eklund, R.C., eds., Handbook of Sport Psychology, 3 Rd edn., John Wiley \& Sons, New York, pp. 113-135.

Côté, J., \& Gilbert, W. (2009). An integrative definition of coaching effectiveness and expertise. International Journal of Sports Science and Coaching, 4(3), pp. 307-323. Feltz, D. L. (1994). Self-confidence and performance. In D. Druckman \& R. A. Bjork (Eds.), Learning, remembering, believing: Enhancing human performance Washington, DC: National Academy Press, pp. 173-206. Feltz, D., Short, S., Sullivan, P. (2008). Self-Efficacy in Sport.pp. 151-176.

Feltz, D., Chase, M., Moritz, S., \& Sullivan, P. (1999). „A conceptual model of coaching efficacy: Preliminary investigation and instrument development", Journal of Educational Psychology, pp. 765-776.

Gioldasis, A., K., Kamenov, E., Bekris. (2013). Leadership style of Greek soccer coaches. Journal of Physical Education and Sport ${ }^{\bullet}$ (JPES), 13(3), Art 56, pp.348 - 353

Horn, T. „Advances in Sport Psychology“. 3rd. Edition, (2008), pp. 240-243.

Hwang, S., Feltz, D. L., \& Lee, J. D. (2013). Emotional intelligence in coaching: Mediation effect of coaching efficacy on the relationship between emotional intelligence and leadership style. International Journal of Sport and Exercise Psychology, 11(3), pp. 292-306.

Iancheva, T., (2012). Self-Confidence and Coaching Efficacy expectations, S., Sport. Stress. Adaptation.

Iancheva, T., Prodanov, G. (2017). Coaching efficacy expectations and specific sources of self-confidence among football coaches, Personality. Motivation. Sport. Sofia: NSA PRESS, pp. 62-68.

Iancheva, T., G. Prodanov (2018) Influence of Emotional intelligence on Coaching efficacy expectations among football coaches, Journal of Applied Sports Sciences, Vol. 2. pp. 59-72.

Kavussanu, M., Boardley, I. D., Jutkiewicz, N., Vincent, S. and Ring, C. M. (2008). Coaching efficacy and coaching effectiveness: examining their predictors and comparing coaches' and athletes' reports. The Sport Psychologist 22, pp. 383-404.

Kavussanu, M., Boardley, I., Jutkiewicz, N., Vincent, S., Ring, R. (2008). Coaching Efficacy and Coaching Effectiveness: Examining Their Predictors and Comparing 
Coaches' and Athletes' Reports. The Sport Psychologist, 2008, 22, 383-404

Lee, K. S., Malete, L., \& Feltz, D. L. (2002). The effect of a coaching education program on coaching efficacy. International Journal of Applied Sport Sciences, 14, pp. 55-67.

Malete, L., \& Feltz, D. L. (2000). The effect of a coaching education program on coaching efficacy. The Sport Psychologist, 14, pp. 410-417.

Myers, N. D., Vargas-Tonsing, T. M., \& Feltz, D. L. (2005). Coaching efficacy in intercollegiate coaches: Sources, coaching behaviour and team variables. Psychology of Sport and Exercise, 6, pp. 129-143.

Myers, N. D., Vargas-Tonsing, T. M., \& Feltz, D. L. (2005). Coaching efficacy in intercollegiate coaches: Sources, coaching behaviour and team variables. Psychology of Sport and Exercise, 6, pp. 129-143.

Philip J. Sullivan \& Aubrey Kent (2003) Coaching Efficacy as a Predictor of Leadership Style in Intercollegiate Athletics, Journal of Applied Sport Psychology, 15:1, pp. 1-11 Short, S. E., Smiley, M., \& Ross-Stewart, L. (2005). The relationship between efficacy beliefs and imagery use in coaches. The Sport Psychologist, 19, pp. 380-394.

Smoll, F. L., Smith, R. E., Curtis, B., \& Hunt, E. (1978). Toward a mediational model of coach-player relationships. Research Quarterly, 49, pp. 528-541.
Sullivan, P., Paquette, K., Holt, N., and Bloom, G. (2012). The relation of coaching context and coach education to coaching efficacy and perceived leadership behaviors in youth sport. Sport Psychol. 26, pp. 122-134.

Teques, P, Duarte D. and Viana J. (2019). Coaches' Emotional Intelligence and Reactive Behaviors in Soccer Matches: Mediating Effects of Coach Efficacy Beliefs. Front. Psychol.

Vincer, D. J. E., \& Loughead, T. M. (2010). The relationship between athlete leader behaviours and cohesion in team sports. The Sport Psychologist, 24, pp. 448-467.

Walach-Bista, Z. (2014). Leadership scale for sports theoretical background and review of psychometric properties research. Ceska Kinantropologie, Vol. 18, No. 3, pp.67-76.

Whitmore, J. (2003). Coaching for performance. London: Nicholas Brealey. 42.

Zhang, J., Jensen, B. E., and Mann, B. L. (1997). Modification and revision of the Leadership.

Corresponding author: Prof. Tatiana Iancheva, DSc National Sports Academy "Vassil Levski" 21 Acad. Stefan Mladenov, str. Sofia, 1000, Bulgaria E-mail: iancheva.tatiana@gmail.com 